\title{
Wavelet based feature extraction for classification of Power Quality Disturbances
}

\author{
Sudipta Nath and Priyanjali Mishra \\ Department of Electrical Engineering \\ Netaji Subhash Engineering College, Garia \\ Techno City, Garia, Kolkata 700152 (India) \\ Phone/Fax number: +0091 33 24361285, e-mail: nath_sudipta@yahoo.com, pyiyanjali.19@gmail.com
}

\begin{abstract}
The detection and classification of power quality disturbances in power systems are important tasks in monitoring and protection of power system network. Most of the power system disturbances are non stationary and transitory in nature and new tools are being used nowadays for the analysis of power quality disturbances. This paper presents a wavelet based feature extraction method for the detection and classification of power quality disturbances. The disturbance waveforms obtained from simulation are decomposed by wavelet packet transform. The energy distribution pattern of the distorted signals has been chosen for feature extraction. Various power quality disturbances have been tested such as voltage sag, interruption, voltage swell, transient, flicker, low frequency and high frequency disturbances
\end{abstract}

\section{Key words}

power quality, wavelet packet transform, energy distribution, power quality disturbance.

\section{Introduction}

Power quality study has become an important subject in recent years because poor power quality may cause many problems for the affected loads such as malfunctions, instabilities, short life time and many others. Hence detection and classification of power quality disturbances is a challenging task for the power system engineers. The disturbance waveforms contain serious imprecision data and directly provide very little information for identification of power quality problems. Hence power quality experts are needed for the development of expert systems which can detect and classify power quality problems.

Wavelet transform in combination with Fourier can extract unique features from voltage and current waveforms that characterize power quality events [1]. The Fourier transform is used to characterize steady state phenomena and the wavelet transform is applied to transient phenomena. The concept of discrete wavelet transform for feature extraction of power disturbance signal combined with fuzzy logic and artificial neural network is a powerful tool for detecting and classifying power quality problems. A wavelet based extended fuzzy reasoning approach for power quality disturbance recognition and identification has been proposed in [2]. To extract power quality disturbance features the energy distribution at different levels of decomposition has been considered and based on these features rule bases are generated for extended fuzzy reasoning. In [3] wavelet based neural network classifier for recognizing power quality disturbances is implemented and tested under different conditions. Here the discrete wavelet transform is integrated with probabilistic neural network model to construct the classifier. The paper [4] employs a different type of univariate randomly optimized neural network combined with discrete wavelet transform and fuzzy logic to have better power quality disturbance classification accuracy. Here the system is modeled using VHSIC hardware description language (VHDL) followed by extensive testing and simulation.

A wavelet feature extraction technique based on norm entropy is proposed in [5] for automatic power quality disturbance classification. The disturbance classification is performed with wavelet neural network. Another wavelet entropy based approach for power system transient classification is presented in [6]. Here neural network is employed for automatic power system transient classification. Based on wavelet transform the idea of entropy and weight coefficient is introduced and the wavelet energy entropy and wavelet entropy weight are defined in [7]. Here also with the help of neural network classifier transient signals have been classified. A novel approach for the recognition of power quality disturbances using multiwavelet transform and neural network is discussed in [8]. Another hybrid methodology using wavelet transform and neural network to automatically detect, locate and classify disturbances affecting power quality is presented in [9]. A new voltage sag detection method based on wavelet transform is developed in [10]. The developed voltage sag detection algorithm is 
implemented with high speed microcontroller and test results show high accuracy and satisfactory voltage sag detection

Energy and entropy based feature extraction technique provides quick and accurate location of faults in transmission lines by using wavelet packet transform and neural network [11]. The extracted features are applied to artificial neural network for estimating fault location. In [12] detection of fault type has been implemented using wavelet analysis together with wavelet entropy principle. The paper [13] illustrates a procedure based on continuous wavelet transform for the analysis of voltage transients due to line faults and discusses its application to fault location in power distribution systems. A novel technique for fault location has been investigated in [14] on parallel transmission lines using wavelet. Wavelet transform can be equally applied for distance protection and digital protection of transmission lines. [15, 16]. Discrete wavelet transform integrated with fuzzy logic system is designed for fault classification of transmission line in [17].

In this paper a wavelet based approach for power quality disturbance recognition and identification has been proposed. To extract power quality disturbance features the energy distribution at each decomposition level has been considered. The types of disturbances under consideration here are sag, swell, interruption, transient, flicker, low frequency and high frequency components.

\section{Feature extraction of power quality disturbances}

The Wavelet Transform (WT), originally derived to process seismic signals, provides a fast and effective way of analyzing non-stationary and non-periodic voltage and current waveforms. The ability of wavelets to focus on short time intervals for high frequency components and long intervals for low frequency components improves the analysis of signals with localized impulses and oscillations, particularly in the presence of a fundamental and low order harmonic. A wavelet is the product of an oscillatory function and a decay function.

The wavelet transform is computed separately for different segments of the time domain signal. The width of the window is changed as the transform is computed for every single spectral component, which is probably the most significant characteristic of the wavelet transform.

Analysis of the signal at different frequencies with different resolution is called Multi Resolution Analysis. MRA is designed to give good time resolution and poor frequency resolution at high frequencies and good frequency resolution and poor time resolution at low frequencies. This approach makes sense especially when the signal at hand has high frequency components for short duration and low frequency components for long duration.

The wavelet packet transform (WPT) is an expansion of classical wavelet decomposition that presents more complex and flexible analysis because in wavelet packet analysis the details as well as the approximations are splitted. The top level of WPT is the time representation whereas the bottom level is the better frequency resolution. Hence with use of WPT a better frequency resolution can be obtained for the decomposed signal.

The wavelet energy is the sum of square of detailed wavelet transform coefficients. The energy of wavelet coefficient is varying over different scales depending on the input signals. The energy of the distorted signal can be partitioned at different resolution levels in different ways depending on the power quality problem. Hence the coefficient of the detailed version at each resolution level has been examined to extract features of the distorted signal for classifying different power quality problems.

The Daubechies"db4" wavelet has been chosen for signal decomposition and number of levels for decomposition has been chosen as 12 .

\section{Simulation and Analysis}

Seven types of disturbance signals have been considered in this paper and they are compared with the purely sinusoidal one. All the signals are of $50 \mathrm{~Hz}$. frequency and amplitude 1 p.u.. The sampling frequency is $12.8 \mathrm{KHz}$. It has been observed that for short duration disturbances such as sag, swell and interruption the energy values at different detail levels do not change much with the change in the deviation in the magnitude of the disturbed signal. The change is found only in the energy value of the approximation. Here energy of the approximation at the highest level is considered. It has been found that magnitude of $\mathrm{a}_{12}$ increases with the increase of sag and decreases with the increase of swell in the signal.

Table I. - Detail level energy distribution for voltage sag

\begin{tabular}{|c|c|c|c|c|}
\hline LEVEL & PURE & SAG 0.5 p.u. & SAG 0.4 p.u. & SAG 0.7 p.u. \\
\hline $\mathrm{d}_{1}$ & 0 & 0 & 0 & 0 \\
\hline $\mathrm{d}_{2}$ & 0 & 0 & 0 & 0 \\
\hline $\mathrm{d}_{3}$ & 0 & 0 & 0 & 0 \\
\hline $\mathrm{d}_{4}$ & 0 & 0 & 0 & 0.01 \\
\hline $\mathrm{d}_{5}$ & 0.02 & 0.03 & 0.03 & 0.04 \\
\hline $\mathrm{d}_{6}$ & 1.13 & 1.19 & 1.17 & 1.26 \\
\hline $\mathrm{d}_{7}$ & 34.49 & 31.6 & 32.24 & 30.33 \\
\hline $\mathrm{d}_{8}$ & 57.12 & 56.04 & 56.26 & 55.63 \\
\hline $\mathrm{d}_{9}$ & 0.16 & 0.32 & 0.27 & 0.46 \\
\hline $\mathrm{d}_{10}$ & 0.47 & 0.77 & 0.7 & 0.94 \\
\hline $\mathrm{d}_{11}$ & 0.14 & 0.33 & 0.28 & 0.43 \\
\hline $\mathrm{d}_{12}$ & 0.06 & 0.26 & 0.2 & 0.39 \\
\hline $\mathrm{a}_{12}$ & 6.40 & 9.45 & 8.84 & 10.52 \\
\hline
\end{tabular}

Simultaneously it has also been observed that with the change in the time of occurrence of the short duration disturbance in the signals the energy values do not change. The change in the energy values is seen only when the duration of short duration disturbances changes. The total duration of the signal considered here is from 0 to $0.36 \mathrm{~s}$. 
For sag and swell of $40 \%, 50 \%$ and $70 \%$ for $0.18 \mathrm{~s}$ duration, the energy values at different levels are shown in Tables I and II.

The disturbance occurs from $0.06 \mathrm{~s}$ to $0.24 \mathrm{~s}$. Table III shows the energy values at different levels of decomposition for swell of $50 \%$ and time of occurrence of disturbance from 0.15 s to $0.33 \mathrm{~s}$. Comparing Table III with table 2 it is seen that the energy values are almost same with the change in the time of occurrence of the signal as the duration of the disturbance is same i.e. $0.18 \mathrm{~s}$. It can be observed that maximum value of energy occurs at level 8 for pure signal as well as for sag and swell. Table IV shows the energy values of the highest approximation level for sag, swell and interruption with duration $0.18 \mathrm{~s}$ each.

Table II. - Detail level energy distribution for voltage swell

\begin{tabular}{|c|c|c|c|}
\hline LEVEL & $\begin{array}{c}\text { SWELL } \\
1.5 \text { p.u. }\end{array}$ & $\begin{array}{c}\text { SWELL } \\
1.4 \text { p.u. }\end{array}$ & $\begin{array}{c}\text { SWELL } \\
1.7 \text { p.u. }\end{array}$ \\
\hline $\mathrm{d}_{1}$ & 0 & 0 & 0 \\
\hline $\mathrm{d}_{2}$ & 0 & 0 & 0 \\
\hline $\mathrm{d}_{3}$ & 0 & 0 & 0 \\
\hline $\mathrm{d}_{4}$ & 0. & 0 & 0 \\
\hline $\mathrm{d}_{5}$ & 0.02 & 0.02 & 0.02 \\
\hline $\mathrm{d}_{6}$ & 1.19 & 1.14 & 1.16 \\
\hline $\mathrm{d}_{7}$ & 36.25 & 35.98 & 36.69 \\
\hline $\mathrm{d}_{8}$ & 57.87 & 57.75 & 58.07 \\
\hline $\mathrm{d}_{9}$ & 0.16 & 0.15 & 0.17 \\
\hline $\mathrm{d}_{10}$ & 0.33 & 0.35 & 0.3 \\
\hline $\mathrm{d}_{11}$ & 0.06 & 0.07 & 0.04 \\
\hline $\mathrm{d}_{12}$ & 0.02 & 0.02 & 0.02 \\
\hline $\mathrm{a}_{12}$ & 4.16 & 4.53 & 3.53 \\
\hline
\end{tabular}

Table III. - Detail level energy distribution of voltage swell for different time of occurrence

\begin{tabular}{|c|c|c|c|}
\hline LEVEL & $\begin{array}{c}\text { SWELL } \\
1.5 \text { p.u. }\end{array}$ & $\begin{array}{c}\text { SWELL } \\
1.4 \text { p.u. }\end{array}$ & $\begin{array}{c}\text { SWELL 1.7 } \\
\text { p.u. }\end{array}$ \\
\hline $\mathrm{d}_{1}$ & 0 & 0 & 0 \\
\hline $\mathrm{d}_{2}$ & 0 & 0 & 0 \\
\hline $\mathrm{d}_{3}$ & 0 & 0 & 0 \\
\hline $\mathrm{d}_{4}$ & 0. & 0 & 0 \\
\hline $\mathrm{d}_{5}$ & 0.02 & 0.02 & 0.02 \\
\hline $\mathrm{d}_{6}$ & 1.15 & 1.14 & 1.16 \\
\hline $\mathrm{d}_{7}$ & 36.02 & 35.98 & 36.69 \\
\hline $\mathrm{d}_{8}$ & 58.26 & 58 & 57.8 \\
\hline $\mathrm{d}_{9}$ & 0.15 & 0.15 & 0.17 \\
\hline $\mathrm{d}_{10}$ & 0.55 & 0.5 & 0.45 \\
\hline $\mathrm{d}_{11}$ & 0.11 & 0.09 & 0.1 \\
\hline $\mathrm{d}_{12}$ & 0.03 & 0.02 & 0.02 \\
\hline $\mathrm{a}_{12}$ & 3.71 & 4 & 3.4 \\
\hline
\end{tabular}

Table $\mathrm{V}$ presents the energy distribution values for all the detail level and the highest approximation level for different types of short duration and transient disturbances. Here the sag is $60 \%$ and swell is $40 \%$. The duration of the disturbances in both cases and for interruption is $0.1 \mathrm{~s}$. The duration of the transient disturbance is $0.05 \mathrm{~s}$. For flicker, low frequency and high frequency disturbances the simulation has been done considering varying frequencies.

It is observed from Tables I and II that for pure sinusoidal signal the energy values at detail level $\mathrm{d}_{7}$ and $\mathrm{d}_{8}$ are much higher than others. The energy values gradually increases from level 1 to level 8 , then decreases slightly at level 9, again increases slightly at level 10 and then gradually decreases. The detail energy distribution pattern for sag and swell are exactly same as that of the pure signal. The short duration disturbances can be easily detected from the approximation values as shown in Table IV. The energy of the approximation $\mathrm{a}_{12}$ is higher in case of sag and lower in case of swell compared to the pure sinusoidal signal. The results of Table $\mathrm{V}$ have been represented graphically in Figs. 1 -8.

Table IV. - Approximation level energy distribution for voltage sag, swell and interruption

\begin{tabular}{|c|c|c|c|c|}
\hline SIGNAL & PURE & SAG & SWELL & INTERRUPTION \\
\hline $\mathrm{a}_{12}$ & 6.4 & 9.45 & 4.16 & 11.2 \\
\hline
\end{tabular}

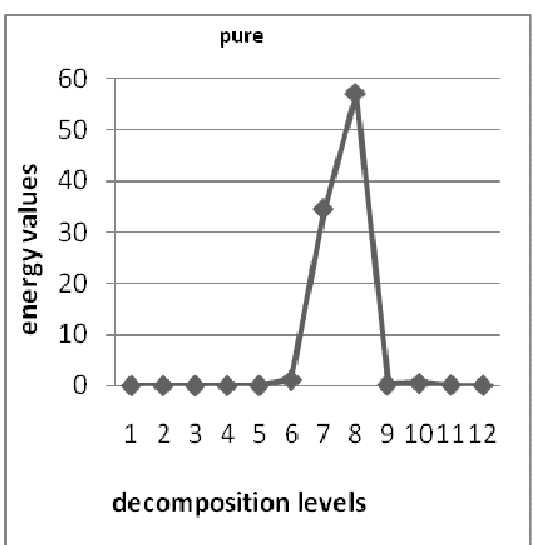

Fig. 1. Energy distribution pattern for pure sinusoidal signal

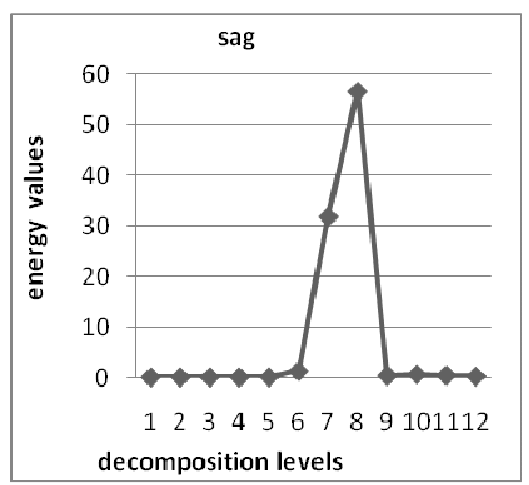

Fig. 2. Energy distribution pattern for voltage sag 
Table V. - Detail level energy distribution for short duration, high frequency and low frequency disturbance

\begin{tabular}{|c|c|c|c|c|c|c|c|c|c|c|c|c|}
\hline TYPE OF SIGNAL & $\mathrm{d}_{1}$ & $\mathrm{~d}_{2}$ & $\mathrm{~d}_{3}$ & $\mathrm{~d}_{4}$ & $\mathrm{~d}_{5}$ & $\mathrm{~d}_{6}$ & $\mathrm{~d}_{7}$ & $\mathrm{~d}_{8}$ & $\mathrm{~d}_{9}$ & $\mathrm{~d}_{10}$ & $\mathrm{~d}_{11}$ & $\mathrm{~d}_{12}$ \\
\hline Pure & 0 & 0 & 0 & 0 & 0.02 & 1.13 & 34.49 & 57.12 & 0.16 & 0.47 & 0.14 & 0.06 \\
\hline Sag & 0 & 0 & 0 & 0 & 0.03 & 1.20 & 32.76 & 56.56 & 0.33 & 0.59 & 0.39 & 0.18 \\
\hline Swell & 0 & 0 & 0 & 0 & 0.02 & 1.14 & 35.37 & 57.45 & 0.19 & 0.35 & 0.21 & 0.03 \\
\hline Interruption & 0 & 0 & 0 & 0 & 0.04 & 1.3 & 31.77 & 56.39 & 0.56 & 0.7 & 0.62 & 0.28 \\
\hline Transient & 0 & 0 & 0.11 & 1.91 & 0.31 & 1.08 & 33.57 & 55.94 & 0.16 & 0.45 & 0.15 & 0.06 \\
\hline Flicker & 0 & 0 & 0.01 & 0.02 & 0.78 & 11.52 & 23.62 & 34.3 & 0.37 & 0.85 & 0.14 & 0.76 \\
\hline Low frequency & 0 & 0 & 0 & 0 & 0.01 & 0.66 & 19.19 & 34.26 & 5.46 & 8.79 & 3.09 & 0.17 \\
\hline Harmonics & 0 & 0 & 0.05 & 0.46 & 4.26 & 11.29 & 8.03 & 15.06 & 0.18 & 0.8 & 0.39 & 0.86 \\
\hline
\end{tabular}

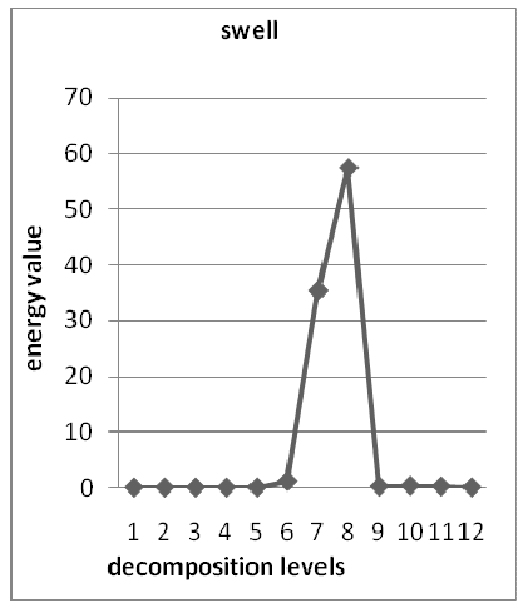

Fig. 3. Energy distribution pattern for voltage swell

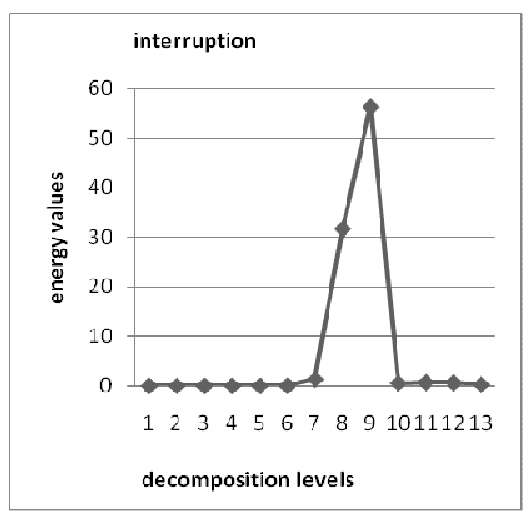

Fig. 4. Energy distribution pattern for interruption

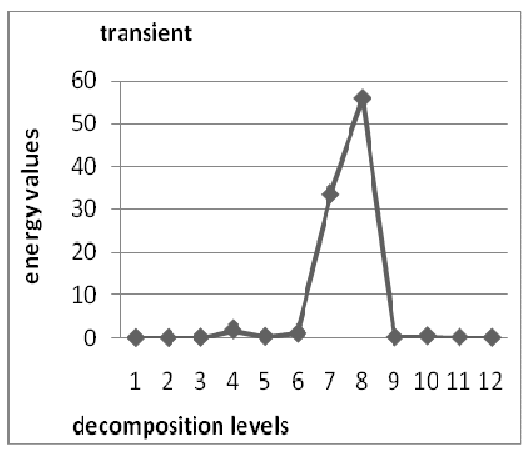

Fig. 5. Energy distribution pattern for transient

Fig. 1, 2, 3 and 4 show the energy distribution pattern of detail level for pure sinusoidal signal and signals with sag, swell and interruption. Fig. 5 and Fig. 6 show the energy distribution pattern of signals with transient disturbance and harmonic content. It is observed from Fig. 5 that there is variation in the energy distribution at the lower level i.e. before level 8 and in Fig. 6 also variations in energy level at the lower level is much more prominent than that at the higher level. Hence it can be concluded that for high frequency disturbance the energy distribution pattern shows variations at the lower level.

Fig. 7 and fig. 8 shows the detail level energy distribution pattern for flicker and low frequency disturbance. It is observed that in both cases the energy distribution pattern shows obvious variations at the higher level i.e. $d_{9}$ to $d_{12}$. 


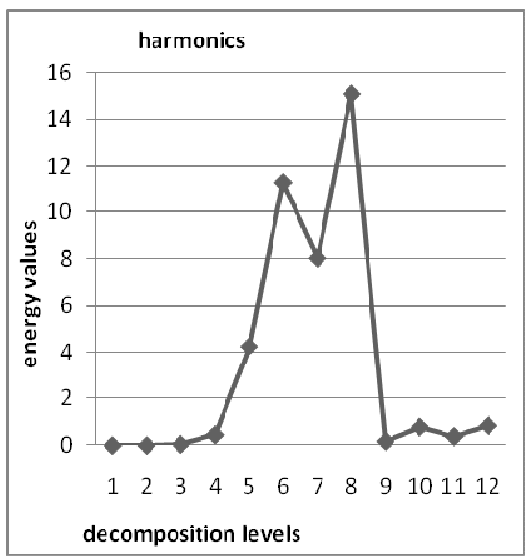

Fig. 6. Energy distribution pattern for harmonic distribution

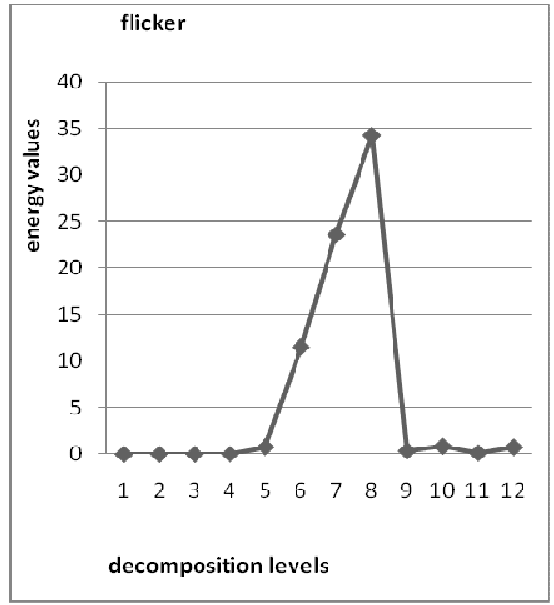

Fig. 7. Energy distribution pattern for flicker

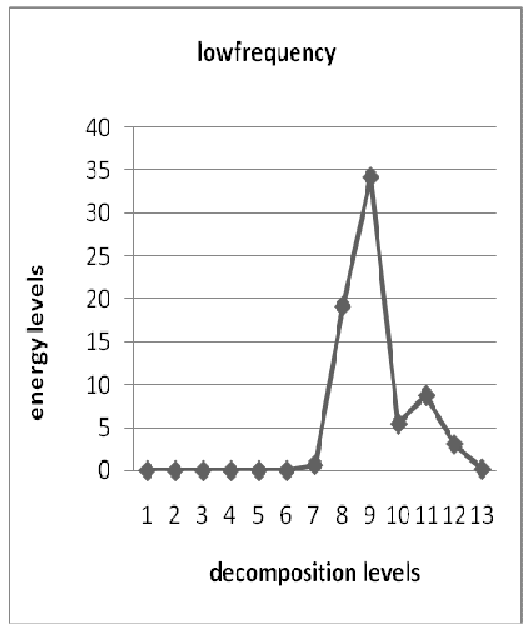

Fig. 8. Energy distribution pattern for low frequency disturbance

\section{Conclusions}

In this paper we have proposed energy based wavelet packet scheme for identification of six kinds of power quality disturbances. The energy distribution patterns in the wavelet domain are used as power quality disturbance features. It has been found that for short duration disturbances such as sag, swell and interruption, the energy distribution remains exactly same irrespective of the time of occurrence and magnitude of the disturbance in the signal. For low frequency disturbance the detail energy shows prominent variations at higher levels and for high frequency disturbance the variations are observed at the lower levels. Using the energy distribution pattern expert systems can be developed which can accurately classify the type of stationary and non stationary disturbances present in the signal.

\section{Acknowledgement}

The authors acknowledge the financial support from All India Council for Technical Education (AICTE), Govt. of India for sponsoring this research in the form of grant-inaid to Career Award for Young Teachers to Dr. Sudipta Nath.

\section{References}

[1] S. Santoso, W. M. Grady, E. J. Powers, J. Lamoree and S. C. Bhatt, "Characterization of distribution power quality events with Fourier and wavelet transforms", IEEE Trans. Power Delivery, vol. 15, pp 247 -254, Jan. 2000.

[2] T. X. Zhu, S. K. Tso, and K. L. Lo, "Wavelet-based fuzzy reasoning approach to power-quality disturbance recognition," IEEE Trans. Power Delivery, vol. 19, pp 1928- 1935, Oct. 2004.

[3] Z. L. Gaing, "Wavelet -based neural network for power disturbance recognition and classification", IEEE Trans. Power Delivery, vol. 19, pp. 1560 -1567, Oct. 2004.

[4] M. B. I. Reaz, F. Choong, M. S. Sulaiman, F. M. Yasin, and M. Kamada, "Expert system for power quality disturbance classifier,” IEEE Trans. Power Delivery, vol. 22, pp 1979-1988, July 2007.

[5] M. Uyar, S. Yilidrim, and M.T. Gencoglu, "An effective wavelet-based feature extraction method for classification of power quality disturbance signals," International journal of Electric power systems research, vol. 78, pp 1747- 1755, 2008.

[6] T. Jayasree, D. Devaraj, R. Sukanesh, "Classification of transients using wavelet based entropy and radial basis neural networks," International Journal of Computer and Electrical Engineering, vol. 1, pp 590-595, Dec. 2009.

[7] Z. He, S. Gao, X. Chen, J. Zhang, Z. Bo, and Q. Qian, "Study of a new method for power system transients classification based on wavelet entropy and neural network", International journal of Electrical power and Energy systems, Article in press , 2010.

[8] S. Kaewarsa, K. Attakitmongcol, T. Kulworawanichpong, "Recognition of power quality events by using multiwaveletbased neural networks," International journal of Electrical power and Energy systems, vol. 30, pp 254-260, 2008.

[9] M. Oleskovicz, D. V. Coury, O. D. Felho, W. F. Usida, A. A.F.M. Carneiro, and L.R.S. Pires, "Power quality analysis applying a hybrid methodology with wavelet transforms and 
neural networks," International journal of Electrical power and Energy systems, vol. 31, pp 206-212, 2009.

[10] O. Gencer, S. Ozturk, and T. Erfidan, "A new approach to voltage sag detection based on wavelet transform," International journal of Electrical power and Energy systems, vol. 32, pp 133140,2010

[11] S. Ekici, S. Yildirim, and M. Poyraz, "Energy and entropybased feature extraction for locating fault on transmission lines by using neural network and wavelet packet decomposition," International journal of Expert Systems with Applications, vol. 34, pp 2937-2944, 2008.

[12] S.El. Safty, and A. El- Zonkoly, "Applying wavelet entropy principle in fault classification", International journal of Electrical power and Energy systems, vol. 31, pp. 604-607, 2009.

[13] A. Borghetti, S. Corsi, C. A. Nucci, M. Paolone, L. Peretto, and R. Tinarelli, "On the use of continuous-wavelet transform for fault location in distribution power systems", International journal of Electrical power and Energy systems, vol. 28, pp. 608617, 2006.

[14] H. Jung, Y. Park, M. Han, C. Lee, H. Park, and M. Shin, "Novel technique for fault location estimation on parallel transmission lines using wavelet," International journal of Electrical power and Energy systems, vol. 29, pp. 76-82, 2007.

[15] S. P. Valsan, and K. S. Swarup, "Wavelet transform based digital protection for transmission lines," International journal of Electrical power and Energy systems, vol. 31, pp. 379-388, 2009.

[16] K. M. Silva, W. L .A. Naves, and B. A. Souza, "Distance protection using a wavelet-based filtering algorithm", International journal of Electric power systems research, vol. 80, pp. 84- 90, 2010.

[17] A. K. Pradhan, A. Routray, S. Pati and D. K. Pradhan, "Wavelet fuzzy combined approach for fault classification of a series-compensated transmission line," IEEE Trans. Power Delivery, vol. 19, pp. $1612-1618$, Oct. 2004. 